\title{
- Short and long-term mortality in acute pulmonary embolism: do new predictors beat old risk scores?
}

\author{
Irzal Hadžibegović*, \\ Olvana Jurin, \\ Vanja Ivanović \\ Mihajlović, \\ Mario Sičaja, \\ Boris Starčević
}

University Hospital Dubrava, Zagreb, Croatia

RECEIVED:

September 10, 2017

ACCEPTED:

September 26, 2017

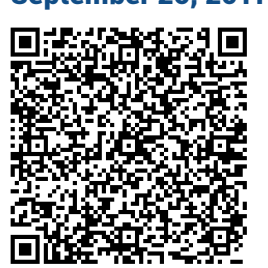

KEYWORDS: pulmonary embolism, mortality, risk score.

CITATION: Cardiol Croat. 2017;12(9-10):381. | https://doi.org/10.15836/ccar2017.381

*ADDRESS FOR CORRESPONDENCE: Irzal Hadžibegović, Klinička bolnica Dubrava, Avenija Gojka Šuška 6, HR10000 Zagreb, Croatia. / Phone: +385-91-5333-091 / E-mail: irzalh@gmail.com

ORCID: Irzal Hadžibegović http://orcid.org/0000-0002-3768-9134 • Ivana Jurin http://orcid.org/0000-0002-2637-9691 Vanja Ivanović Mihajlović http://orcid.org/0000-0001-6931-5404 • Mario Sičaja http://orcid.org/0000-0003-0773-4720 Boris Starčević http://orcid.org/0000-0002-3090-2772

IIIIIIIIIIIIIIIIIIIIIIIIIIIIIIIIIIIIIIIIIIIIIIIIIIIIIIIIIIIIIIIIIIIIIIIIIIIIIIIIIIIIIIIIIIIIIIIIIIIIIIIIIIIIIIIII

Background: Numerous prognostic indicators for acute pulmonary embolism (PE) have been proposed, with Pulmonary embolism severity index (PESI) being the most studied and most accepted risk score and predictor of mortality. ${ }^{1,2}$ We analyzed PESI and classical prognostic factors, and compared it with fast and simple blood count tests as predictors of mortality.

Patients and Methods: We analyzed 299 patients treated for acute PE between 2013 and 2016. Median follow up time was 16 months (range 55 months). Multivariate Cox proportional hazard regression models for 30-day, 12-month and 48-months mortality were obtained, combining gender, age, malignancy history, PESI score, atrial fibrillation, positive troponin-I, C-reactive protein (CRP), main branch involvement on MSCT, red cell distribution width (RDW), mean platelet volume (MPV), and platelet to lymphocyte ratio.

Results: Thirty-day survival was $82.3 \%$, whereas 12 -months and 48 -months survival was $69.6 \%$ and $66.2 \%$, respectively. Statistically significant effect on 30 -day mortality was shown for higher PESI score (HR 1.027, CI 1.020-1.034; p=0.000), higher RDW (HR 1.301, CI 1.144-1.481; p=0.000), malignancy (HR 2.886, CI 1.366-6.101; $\mathrm{p}=0.006$ ), higher CRP (HR 1.034, CI 1.006-1.062; $\mathrm{p}=0.016$ ), and higher platelet to lymphocyte ratio (HR 1.001, CI 1.000-1.002; $\mathrm{p}=0.026$ ). Statistically significant effect on 12-months mortality was shown for higher PESI score (HR 1.020, CI 1.015-1.025; p=0.000), higher RDW (HR 1.332, CI 1.225-1.449; $\mathrm{p}=0.000$ ), and higher platelet to lymphocyte ratio (HR 1.001, CI 1.000-1.002; $\mathrm{p}=0.013$ ). Statistically significant effect on 48-months mortality was shown for higher PESI score (HR 1.020, CI 1.015-1.025; p=0.000), higher RDW (HR 1.339, CI 1.234-1.453; p=0.000), malignancy (HR 1.713, CI 1.024-2.868; p=0.040), higher CRP (HR 1.021, CI 1.002-1.041; p=0.032), and higher platelet to lymphocyte ratio (HR 1.001, CI 1.000-1.002; $\mathrm{p}=0.006)$.

Conclusion: Steep decline in survival rate was noted within first 12 months. PESI score above 111 and elevated RDW above 14.5 were the strongest and most consistent predictors of short term and longterm mortality. RDW outperformed PESI in predicting 12-months survival. Future prospective studies of simple blood count derived risk scores are warranted.

LITERATURE IIIIIIIIIIIIIIIIIIIIIIIIIIIIIIIIIIIIIIIIIIIIIIIIIIIIIIIIIIIIIIIIIIIIIIIIIIIIIIIIIIIIIIIIIIIIIIIIIIII

1. Akgüllü Ç, Ömürlü IK, Eryılmaz U, Avcil M, Dağtekin E, Akdeniz M, et al. Predictors of early death in patients with acute pulmonary embolism. Am J Emerg Med. 2015 Feb;33(2):214-21. https://doi.org/10.1016/j.ajem.2014.11.022

2. Liu X, Chang S, Fu C, Huo Z, Zhou J, Liu C, et al. Predictors of mid-term prognosis and adverse factors in acute pulmonary embolism. Ther Adv Respir Dis. 2017 Aug;11(8):293-300. https://doi.org/10.1177/1753465817717168 